\title{
Aortic valve replacement with the Mitroflow pericardial bioprosthesis: Durability results up to 21 years
}

\author{
Charles A. Yankah, MD, PhD, Miralem Pasic, MD, PhD, Michele Musci, MD, Julia Stein, MSc, \\ Christine Detschades, SRN, Henryk Siniawski, MD, PhD, and Roland Hetzer, MD, PhD
}

Objective: The study aim was to analyze the performance profile of a large series of Mitroflow pericardial valves (Sorin Group Canada Inc. Mitroflow Division) in the very long term.

Methods: Data from 1513 patients with isolated aortic valve replacement who received pericardial bioprostheses between 1986 and 2007 were analyzed. Cumulative duration of follow-up was 6164 patient-years with a maximum duration of 21 years. Actuarial rates of valve-related events were calculated by the Kaplan-Meier method and the Cox multivariate analysis to identify independent determinants of outcome.

Results: Hospital mortality for elective surgery was $2.5 \%$. Late death was $40.6 \%$. Reoperation was required in $86(5.7 \%)$ patients and was valve related in 83: structural valve deterioration in $64(4.2 \%)$ patients, prosthetic valve endocarditis in 17 patients $(1.1 \%)$, valve thrombosis in 1 , and periprosthetic leak in 1 . Rates of 20 -year actuarial freedom from valve-related morbidity were as follows: structural valve deterioration $84.8 \%$ (actual $96.6 \%$ ) in patients 70 years of age or older; thromboembolism $94.1 \%$; and prosthetic valve endocarditis $96.8 \%$. Twenty-year actual risk of reoperation for structural valve deterioration was $11.4 \%$ in all patients and $3.4 \%$, in patients 70 years or age or older. Advanced age, renal insufficiency, pulmonary disease, and low body mass index were independent risk factors for late outcome $(P<.001)$.

Conclusions: After 2 decades of follow-up, the Mitroflow pericardial aortic valve continues to be a valve of choice with a predictable low rate of valve-related events, particularly for patients over the age of 65 to 70 years and others with comorbidities.

From the Deutsches Herzzentrum Berlin, Berlin, Germany.

Charles Yankah reports consulting and lecture Fees From Sorin.

Received for publication Nov 12, 2007; revisions received March 28, 2008; accepted for publication May 13, 2008.

Address for reprints: A. Charles Yankah, MD, PhD, Professor of Surgery, Humboldt, Charité Medical University, German Heart Institute Berlin, Augustenburger Platz 1, D13353 Berlin, Germany (E-mail: yankah@ dhzb.de).

J Thorac Cardiovasc Surg 2008;136:688-96 $0022-5223 / \$ 34.00$

Copyright $(\underset{2008}{ } 20 \mathrm{by}$ The American Association for Thoracic Surgery

doi:10.1016/j.jtcvs.2008.05.022

\section{A} lthough the pericardial bioprosthesis was once unpopular for clinical use because of design-related early structural deterioration, ${ }^{1-3}$ it has demonstrated its potential for midterm and long-term durability beyond 15 years. ${ }^{4-11}$ It is now apparent that durability and performance resulting from improved design of second-generation pericardial tissue valves are even better when the valves are implanted in a selected group of patients. ${ }^{6-11}$ The Mitroflow pericardial bioprosthesis (Sorin Group Canada Inc. Mitroflow Division) has demonstrated excellent hemodynamics, comparable with stentless porcine valves and superior to similar stented bioprostheses, ${ }^{8,12-20}$ especially in small sizes. The very long-term durability is not yet established. For this reason, we evaluated clinical data from 1513 patients who received single Mitroflow pericardial aortic valve replacement from March 1986 to determine the long-term clinical durability and threshold age for implantation.

\section{Patients and Methods}

Over a period of 21 years between March 1986 and December 2007, 1760 Mitroflow pericardial bioprostheses were implanted in 1722 consecutive patients in the aortic, mitral, tricuspid, and pulmonary positions as single, double, or triple procedures. A total of 1513 patients received single aortic valve replacements. There were 1071 (70.8\%) women and 442 (29.2\%) men. Preoperative characteristics of the study population are shown in Table 1. 


\section{Abbreviations and Acronyms \\ NYHA $=$ New York Heart Association \\ $\mathrm{CI}=$ confidence interval \\ $\mathrm{CL}=$ confidence limits \\ $\mathrm{OR}=$ odds ratio \\ PVE = prosthetic valve endocarditis \\ SVD = structural valve deterioration \\ $\mathrm{TE}=$ thromboembolism}

TABLE 1. Characteristics of patients

\begin{tabular}{|c|c|c|}
\hline No. of patients & & 1513 \\
\hline Mean age (y) & & $73.2 \pm 0.22$ (SEM) \\
\hline Range (y) & & $22-95$ \\
\hline Female & & $1071(70.8 \%)$ \\
\hline Male & & $442(29.2 \%)$ \\
\hline \multicolumn{3}{|l|}{$\begin{array}{l}\text { Distribution of } \\
\quad \text { patients by age group }\end{array}$} \\
\hline Age $(y)$ & $n$ & $\%$ \\
\hline$<60$ & 89 & 5.8 \\
\hline $60-69$ & 366 & 24.2 \\
\hline $70-79$ & 722 & 47.7 \\
\hline$\geq 65$ & 1324 & 87.5 \\
\hline$\geq 70$ & 1058 & 69.9 \\
\hline$\geq 80$ & 336 & 22.2 \\
\hline \multicolumn{3}{|l|}{$N Y H A$} \\
\hline II & & $620(41 \%)$ \\
\hline III & & $633(41.8 \%)$ \\
\hline IV & & $210(13.9)$ \\
\hline Unknown & & $50(3.3 \%)$ \\
\hline \multicolumn{3}{|l|}{ Body mass index } \\
\hline Mean $\left(\mathrm{kg} / \mathrm{m}^{2}\right)$ & & $25.74 \pm 0.12$ (SEM) \\
\hline Range $\mathrm{kg} / \mathrm{m}^{2}$ & & $12.98-47.5$ \\
\hline Renal failure & & $159(10.5 \%)$ \\
\hline Pulmonary disease (COPD) & & $152(10 \%)$ \\
\hline Carotid stenosis & & $104(6.9 \%)$ \\
\hline \multicolumn{3}{|l|}{ Aortic valve pathomorphology } \\
\hline Aortic stenosis & & $707(46.7 \%)$ \\
\hline Aortic incompetence & & $278(18.4 \%)$ \\
\hline Mixed lesion & & $487(32.2 \%)$ \\
\hline Prosthesis dysfunction & & $41(2.7 \%)$ \\
\hline Etiology & & $N$ \\
\hline Degenerative & & 1217 \\
\hline Congenital & & 13 \\
\hline Acute/subacute endocarditis & & 40 \\
\hline Healed endocarditis & & 202 \\
\hline Prosthesis dysfunction & & 41 \\
\hline \multirow[t]{2}{*}{ CABG procedure } & & $759(50.2 \%)$ \\
\hline & $\begin{array}{l}\text { Implanted } \\
\text { valve size } \\
(N=1513)\end{array}$ & $\begin{array}{l}\text { Explanted } \\
\text { valve size } \\
(N=86)\end{array}$ \\
\hline $19 \mathrm{~mm}$ & $204(13.5 \%)$ & $10(0.7 \%)$ \\
\hline $21 \mathrm{~mm}$ & $869(57.4 \%)$ & $35(2.3 \%)$ \\
\hline $23 \mathrm{~mm}$ & $347(22.9 \%)$ & $30(2.0 \%)$ \\
\hline $25 \mathrm{~mm}$ & $76(5.0 \%)$ & $6(0.4 \%)$ \\
\hline $27 \mathrm{~mm}$ & $17(1.1 \%)$ & $1(0.06 \%)$ \\
\hline Unknown & & $4(0.3 \%)$ \\
\hline
\end{tabular}

NYHA, New York Heart Association; COPD, chronic obstructive pulmonary disease; $C A B G$, coronary artery bypass grafting; $S E M$, standard error of the mean.

ography was performed at different institutions in a uniform manner and the evaluations were comparable. If a patient had undergone more than one echocardiographic or clinical evaluation, the result of the most recent investigation was reported.

We evaluated 189 measurements of mean gradients in 121 patients. Measurement of mean gradients and time intervals between proper selection of the pericardial valve size, using clinical judgpre space in the supra-annular area of the aortic sinuses. this will avoid oversizing, which creates valve deformation. In sitincision or preferably resection (myectomy) should be performed. Enlargement of a small aortic annulus is rare, but if it is necessary the Nicks procedure can be performed to avoid squeezing and deforation of the valve. served.

The valve should be inserted in a supra-annular position to avoid hemodynamic stress, and the valve commissures should correspond to native commissures while the valve sinuses face the coronary osto achieve unobstructed coronary ostia. Finally, very tall kno that would expose valve tissue to abrasion, early alteration, and per-

\section{Data Collection and Postoperative Follow-up}

The study, as well as the use of patients' data for research purposes informed consent was obtained from the follow-up patients. sicians, and cardiologists. Patients with unknown addre could be tracked through the district or state registry of residents or birth and deaths.

Total follow-up was 6163.5 patient-years (mean: $4.07 \pm 0.12$ years, SEM). Eleven $(0.7 \%)$ patients were lost to follow-up (99.3\% complete). A total of 1297 (85.7\%) of the hospital survivors underwent routine echocardiographic studies at 3 and 9 months after operation and thereafter annually. Transthoracic Doppler echocardi- 
serial echocardiographic studies were not uniform in some patients. Therefore, we did not apply the mixed model longitudinal regression analysis as described by Banbury and associates. ${ }^{4} \mathrm{We}$ are presenting scatterplots of mean gradients of valve sizes 19 to $25 \mathrm{~mm}$ and their median values to demonstrate the evolution of transvalvular mean gradients across time.

Structural and nonstructural valve deterioration of Mitroflow bioprostheses, diagnosed preoperatively by echocardiographic studies, was confirmed at the time of explantation.

At the time of the last follow-up study, 150 patients (29\%) were in New York Heart Association (NYHA) class I, 232 (45\%) in class II, $120(23 \%)$ in class III, and $14(3 \%)$ patients could not be classified because of advanced age.

Ninety-seven $(7.6 \%)$ patients were receiving anticoagulation treatment with warfarin sodium (Coumadin) and $260(20.5 \%)$ with antiplatelet drugs. Three hundred fifteen $(24.8 \%)$ patients 65 years of age or older were receiving anticoagulants as compared with $42(3.3 \%)$ patients younger than 65 years.

NYHA functional classification of the patients was inconsistent and unreliable to reproduce owing to a high proportion of patients at advanced age (mean age at operation 73 years). Many follow-up patients discontinued or irregularly took their drugs partly because of the risk and fear of bleeding and stroke. Therefore, a statistical approach to estimate a time-related proportion of patients in NYHA functional class and receiving anticoagulants did not yield meaningful, reproducible clinical information.

Statistics. The probability of survival, freedom from valve-related morbidity events, death, and reoperation were estimated by Kaplan-Meier actuarial analysis and by linearized occurrence rates. Linearized occurence rates of events and confidence limits were calculated according to Poisson distribution.

Actual competing risk analysis (cumulative incidence) was performed.

Tabular data are summarized by the mean and given with standard error for continuous variables and by percentages for categorical variables. Differences in actuarial freedom between groups of patients are determined by the log-rank test. Differences in prognostic variables between two groups were evaluated by $t$ tests for continuous variables and the $\chi^{2}$ or Fisher exact test for categorical variables. Predictors of events during follow-up were identified by the Cox proportional hazards regression.

All variables listed in Table 1 were investigated for association with hospital death, overall death, and valve-related complications by univariate and multivariate analysis. Standard statistical formulas have been used for the analysis of data, as described previously. ${ }^{8}$

\section{Results}

\section{Patient Survival}

Hospital survival. Thirty-day hospital survival was $97.5 \%$ for elective patients and $90.2 \%$ for patients in NYHA functional class III-IV (odds ratio [OR], 3.9; confidence interval [CI] (95\% confidence limits [CL]) 1.3112.07; $P$ value .015).

The causes of early death were cardiac related in $96(61 \%)$ patients and noncardiac and nonvalve related in 61 (39\%) patients. Significant predictive factors for early mortality were emergency operation (OR, 1.53; CI [95\% CL] 1.33-1.75;
$P$ value $<.001)$ and preoperative renal failure $(\mathrm{OR}, 2.76$; CI [95\% CL] 0.98-7.76; $P$ value .054).

Long-term survival. A total of 615 patients died. Twentyfive $(4.1 \%)$ deaths were valve related. Actuarial freedom from valve-related death at 20 years was $82.9 \% \pm 4.0 \%$.

The actuarial survival including operative death in our cohort at 10, 15, and 20 years was $31.9 \% \pm 1.8 \%, 12.7 \% \pm$ $1.4 \%$, and $6.1 \% \pm 1.5 \%$, respectively (Figure 1; OR, 1.82; CI [95\% CL] 1.55-2.18; $P$ value $<.001)$. Univariate and multivariate analysis showed that NYHA III-IV (OR, 1.37; CI [95\% CL] 1.18-1.59; $P$ value $<.001)$, renal insufficiency (OR, 1.74; CI [95\% CL] 1.40-2.17; $P$ value $<.001$ ), chronic obstructive pulmonary disease (OR, 1.54; CI [95\% CL] $1.22-$ 1.95; $P$ value .001), body mass index less than $20 \mathrm{~kg} / \mathrm{m}^{2}(\mathrm{OR}$, 1.46; CI [95\% CL] 1.13-1.88; $P$ value .001), and advanced age (OR, 1.82; CI, 1.56-2.16; $P$ value $<.001)$ were predictive factors for late death.

On the other hand, small valve size (19 mm: OR, 1.09; CI, 0.86-1.38; $P$ value $0.458 ; 21 \mathrm{~mm}$ : OR, 1.68; CI, 0.65-4.38: 1.38; $P$ value .286) and gender (OR, 1.11; CI, 0.96-1.29; $P$ value .158) were not independent risk factors.

Of 435 follow-up patients, after 1 year 136 were in NYHA class I, 202 in class II, 87 in class III, and 10 in class IV; after 5 years, of 45 patients 6 were in class I, 19 in class II, 18 in class III, and 2 in class IV; after 10 years, of 36 patients 8 were in class I, 11 in class II, 15 in class III, and 2 in class

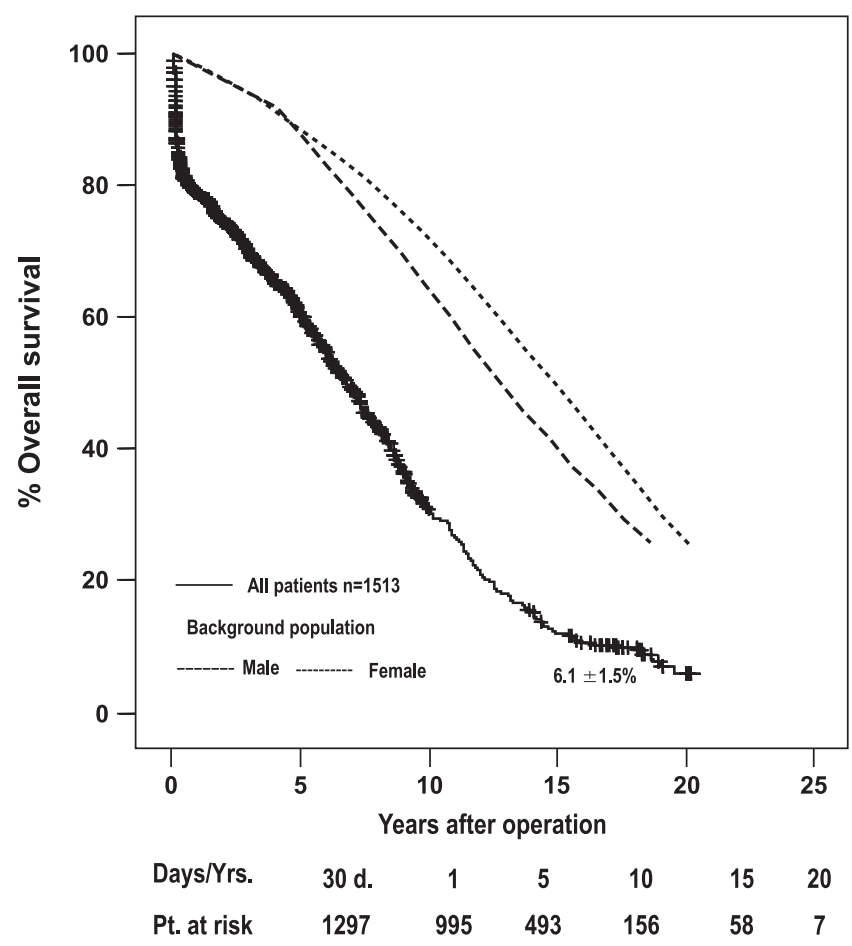

Figure 1. Overall cumulative survival of all 1513 patients after aortic valve replacement and of a German population as background (data from Federal Bureau for Population Statistics, Wiesbaden, Germany). 
IV; after 15 years, of 6 patients 1 was in class I, another 1 in class II, 3 were in class III, and 1 in class IV. Anticoagulation was administered in all patients for 6 weeks after discharge. After 1 year 138 of 995 follow-up patients were receiving anticoagulants, after 5 years 116 of 493, after 10 years 52 of 156, and after 15 years 51 of 58 follow-up patients were receiving anticoagulants.

\section{Valve-related Complications}

Reoperation. Reoperation was required in 86 patients and was valve related in 83. Causes were as follows: structural valve deterioration (SVD) in $64(4.2 \%)$ cases, valve thrombosis in 1 case $(0.07 \%)$, periprosthetic leak in 1 case $(0.07 \%)$, and prosthetic valve endocarditis (PVE) in 17 (1.1\%) cases.

The 20-year actual risk of reoperation for all causes was $15.5 \%$ with a linearized rate of $1.4 \% / \mathrm{pt}-\mathrm{y}$ (CI, 1.05-1.62).

SVD. Sixty-four $(4.2 \%)$ patients had primary tissue failure resulting from leaflet calcification or fibrosis causing stenosis in 8, incompetence in 30 (including 1 leaflet tear in Mitroflow early experience), or mixed lesion in 26 patients. Detailed analysis is shown in Table 2. Overall 20-year freedom from SVD was $62.3+5.02 \%$. Actuarial freedom from reoperation for SVD at 20 years in patients aged 65 years or older and 70 years or older was $71.8 \% \pm 6.0 \%$ (actual, $92.6 \pm 4.6 \%$ ) and $84.8 \pm 0.7 \%$ (actual, 96.6\% $\pm 0.8 \%$ ), respectively (Figures 2-4 and Table 3). The 20-year actual risk (cumulative incidence) for SVD was $11.4 \%$. The linearized rate of SVD for the entire patient cohort was $0.9 \% / p t-y$. It was $0.76 \% / p t-y$ and $0.34 \% / p t-y$ for patients aged 65 years or older and 70 years or older, respectively. Younger patients, below the age of 65 years, had a linearized rate for SVD of 2.1\%/pt-y $(P=.004)$. Detailed linearized rates of events and confidence limits at different age groups are shown in Table 3.

The leaflet disruption observed in 1 patient occurred at the base of the commissural site facing the noncoronary aortic annulus (linearized rate, $0.016 \% / \mathrm{pt}-\mathrm{y}$; CI, 0.0004-0.08).

Time-related transvalvular mean gradients and valve size. Repeated measurements of transvalvular mean gradients and valve sizes across time are shown in Table 4 and Figure 5. Postoperative transvalvular mean gradient with valve

TABLE 2. Summary of causes for reoperation and explantation of 86 Mitroflow valves

\begin{tabular}{lr}
\hline \multicolumn{1}{c}{ Causes } & $\mathbf{n}$ \\
\hline SVD & 63 \\
Leaflet tear & 1 \\
PVE & 17 \\
Periprosthetic leak & 1 \\
Valve thrombosis & 1 \\
Technical & 2 \\
Intraop. mismatch & 1
\end{tabular}

$S V D$, Structural valve deterioration; $P V E$, prosthetic valve endocarditis. *Perivalvular abscess $=1$; leaflet tear $=1$.

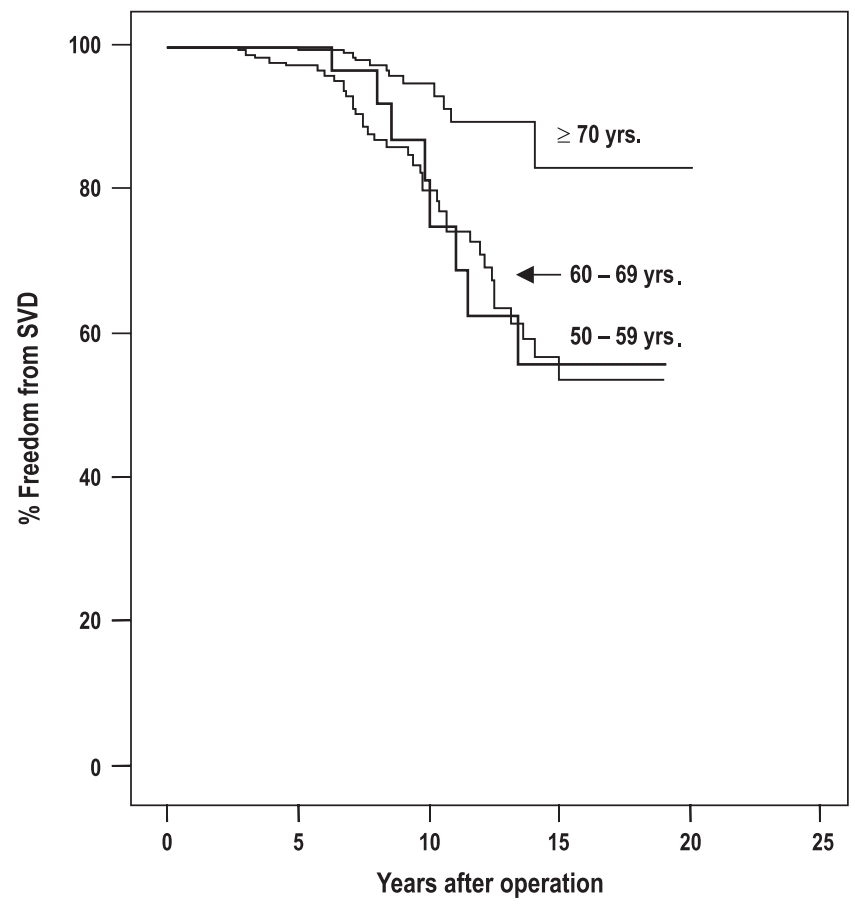

Figure 2. Actuarial freedom from reoperation for structural valve deterioration (SVD) in age groups $(50-59,60-69$, and $\geq 70$ years) after pericardial aortic valve replacement.

size $19 \mathrm{~mm}$ was greater than that with $21 \mathrm{~mm}$ and $23 \mathrm{~mm}$; however, all were decreased at 1 year.

In patients aged 65 years or more, mean transvalvular gradient at 5 years for valve sizes 19 to $25 \mathrm{~mm}$ was 12 to $6 \mathrm{~mm}$ $\mathrm{Hg}$. This increased to 18 to $8 \mathrm{~mm} \mathrm{Hg}$ after 10 years and then remained stable at 15 and 20 years for valve sizes 21 and 23 $\mathrm{mm}$, respectively (Figure 5).

In contrast, patients less than 65 years showed a significant increase in transvalvular mean gradient to 40 to $19 \mathrm{~mm} \mathrm{Hg}$ or more after 10 years for valve sizes 21 and $23 \mathrm{~mm}(P=.004)$, leading to reoperation (Figure 2).

Nonstructural valve dysfunction. There was $1(0.07 \%)$ case of nonstructural valve dysfunction: periprosthetic leak $(0.07 \%)$. An additional 3 dysfunctions were not valve related: 2 technically related $(0.13 \%)$ and 1 intraoperative mismatch $(0.07 \%)$ (Table 2).

Thromboembolism. Forty-nine (3.2\%) patients had episodes of thromboembolsm (TE) representing an actuarial freedom of $94.1 \%$ at 20 years (Figure 6). The linearized rate was $0.79 \% / \mathrm{pt}-\mathrm{y} .(\mathrm{CI}, 0.60-1.01)$. TE occurred in 6 $(0.4 \%)$ patients under 65 years of age (linearized rate, $0.5 \% / p t-y ; C I, 0.24-1.06)$ and in $43(2.8 \%)$ patients 65 years of age or older (linearized rate, $0.93 \% / p t-y ; C I, 0.66-1.18$ ). In the 49 patients with stroke, 4 neurologic events were permanent (linearized rate, $0.06 \% / \mathrm{pt}-\mathrm{yr}$ ) and 9 (linearized rate, $0.09 \% / p t-y r ; ~ C I, 0.07-0.25)$ were fatal. TE was recurrent in 
TABLE 3. Summary of linearized rate of events by age group: Patients at risk and confidence limit

\begin{tabular}{|c|c|c|c|c|c|c|c|}
\hline Age & \multicolumn{7}{|c|}{ Patients at risk } \\
\hline Years & 1 & 5 & 10 & 15 & 20 & $\begin{array}{l}\text { Linearized rate } \\
\% / p t, y r\end{array}$ & $C L$ \\
\hline $50-59$ & 58 & 36 & 14 & 4 & 一 & 1.9 & $1.78-14.78$ \\
\hline $60-69$ & 269 & 156 & 61 & 17 & - & 2.0 & $1.33-2.67$ \\
\hline$\geq 65$ & 853 & 401 & 100 & 20 & 1 & 0.76 & $0.6-1.3$ \\
\hline$\geq 70$ & 658 & 291 & 61 & 9 & 1 & 0.4 & $0.22-0.73$ \\
\hline
\end{tabular}

nine patients. One patient experienced a valve thrombosis (linearized rate: $0.02 \% / \mathrm{pt}-\mathrm{y}$ ).

Bleeding. There were 4 nonfatal cases of hemorrhagic events under anticoagulation therapy (linearized rate, $0.065 \% / \mathrm{pt}-\mathrm{y}$; CI, 0.02-0.15) The indication for anticoagulation was atrial fibrillation or cardiologic decision. None of the patients experienced a recurrent bleeding episode.

$\boldsymbol{P V E}$. Seventeen $(1.1 \%)$ patients with a sterile aortic root at primary operation had a prosthetic infection. The organisms associated with late infections were staphylococcal and streptococcal species. Among the 202 patients with healed endocarditis and 40 with active endocarditis, there was 1 episode of reinfection in each group. Significant paravalvular leaks resulting from infection were observed in 5 patients (linearized rate, 0.08\%/pt-y; CI, 0.03-0.17) and a leaflet tear in 1 of the patients.

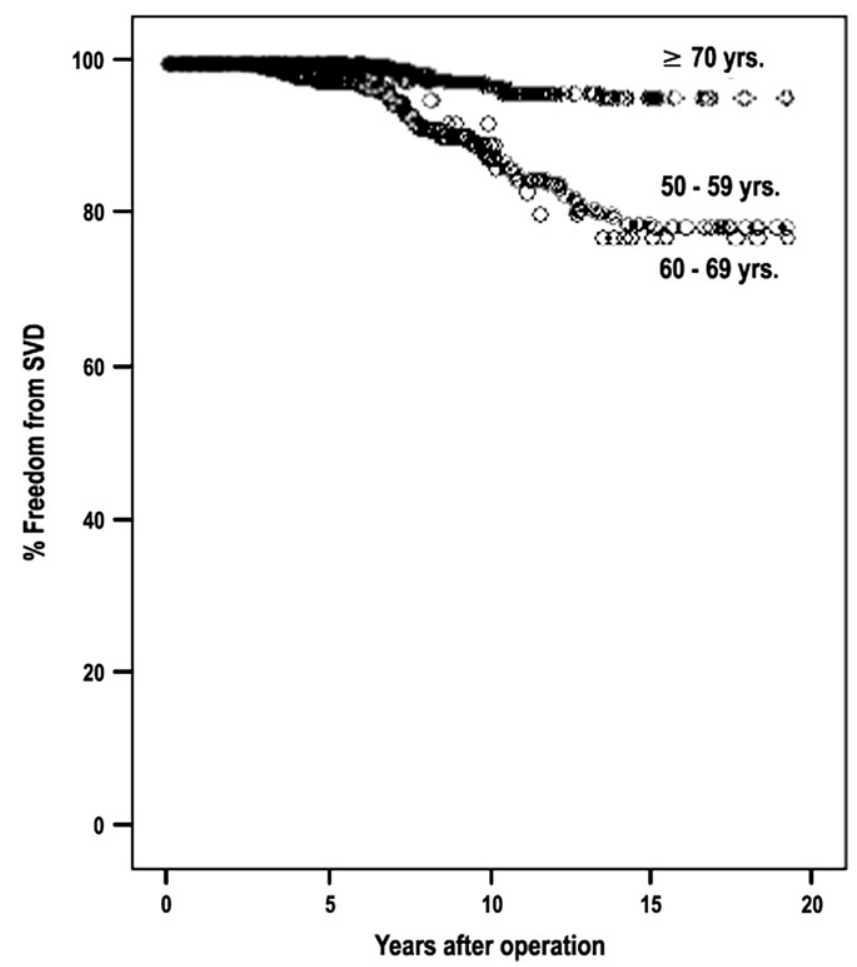

Figure 3. Actual (cumulative incidence) freedom from reoperation for structural valve deterioration (SVD) by age group (50-59, 60-69 and $\geq \mathbf{7 0}$ years) after pericardial aortic valve replacement.
The actuarial freedom from endocarditis was $96.8 \% \pm$ $0.9 \%$ at 20 years and the linearized rate for endocarditis was $0.28 \% / p t-y$ (CI, 0.14-0.44, Figure 7). There were constant very low hazard events of PVE.

\section{Discussion}

Our current series of 1513 Mitroflow stented low-profile pericardial bioprostheses represents one of the largest single institutional experience with the longest follow-up (21 years).

For xenograft tissue valves, the porcine bioprosthesis is taken as the standard against which results can be compared. The potential for a very long-term durability of stented pericardial and stented porcine tissue valves for over 20 years has been demonstrated and reported recently. ${ }^{8,21,22}$

Statistical comparison between actuarial data reported from various institutions is very difficult, but literature review can help to gain a general impression. $5,8,17,18,20,23-25$

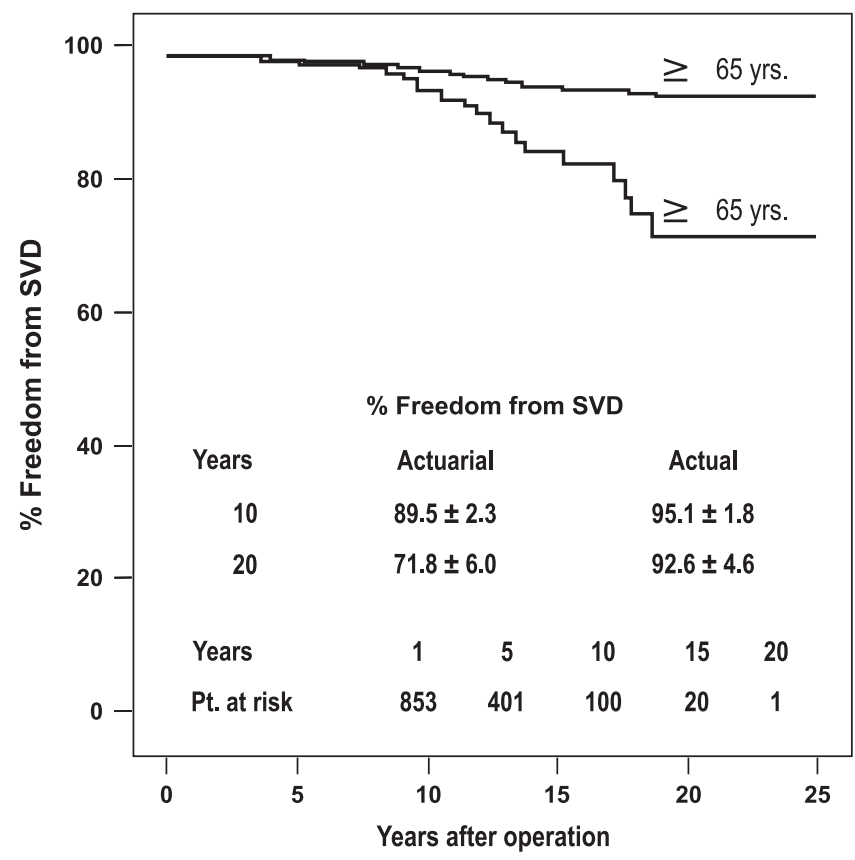

Figure 4. Actuarial and actual (cumulative incidence) freedom from reoperation for structural valve deterioration (SVD) in age group $\geq 65$ years after pericardial aortic valve replacement. 
Although the porcine and pericardial valves are collagen structures treated with glutaraldehyde, their shape, technique of mounting, mode of function, and fluidodynamic characteristics are dissimilar and therefore their long-term performance and mode of failure may be different.

Twenty-one-year durability of the Mitroflow pericardial bioprosthesis attests to the quality of the pericardial tissue and the design/shape of this bioprosthesis. In comparison with porcine valves, the Mitroflow pericardial valve is less obstructive especially in the 19- and 21-mm sizes and even competes well with porcine stentless valves. ${ }^{8,14-20}$ Sustained long-term durability over 21 years has been demonstrated in patients older than 70 years with $84.8 \%$ (actual, 96.6\%) free of SVD.

The 72\% 21-year actuarial (actual, 92.6\%) freedom from SVD in patients over 65 years with Mitroflow pericardial tissue valves compares favorably with Hancock II (Medtronic, Inc, Minneapolis, Minn) porcine valves (actuarial freedom from SVD of 73\%.) in patients in similar age groups. ${ }^{21}$ Other reports also confirmed that the pericardial valve is as durable as porcine and allograft valves at ages above 65 years. ${ }^{24}$

Several authors have reported leaflet tears and early SVD even in elderly patients, which was a rare event in our series. ${ }^{1-3,5,21,26}$ The etiology of early SVD associated with leaflet tears in a subgroup of elderly patients is not clearly understood.

In our series, leaflet tears or disruptions occurred in 2 patients. Leaflet tear as a primary tissue failure occurred in 1 patient, which represents a linearized rate of $0.02 \% / \mathrm{pt}-\mathrm{y}$ (CI, 0.0004-0.08), whereas the other leaflet tear was associated with PVE. This indicates that if there is a history of endocarditis, as we encountered in our patient, the tear is secondary to the infection and the complication has to be classified as endocarditis and excluded from the SVD group, as reported in the guidelines of Edmunds and associates ${ }^{27}$ and by other authors. ${ }^{21,29,30}$ Acceleration of structural deterioration could occur after a successful treatment of endocarditis. ${ }^{7,28}$ It is therefore important to consider the history of previous antibiotic treatment and exclude endocarditis as an underlying cause before classifying a tear as a primary tissue failure.

The analysis of our 21-year results with Mitroflow pericardial bioprostheses in the aortic position has shown it to be

TABLE 4. Postoperative echocardiographic data and labeled prosthesis size in 121 patients

\begin{tabular}{lrcc}
\hline & & \multicolumn{2}{c}{ Mean gradient (mm Hg) } \\
\cline { 3 - 4 } Prosthesis size $(\mathbf{m m})$ & $\mathbf{n}$ & Range & Median \\
\hline 19 & 18 & $7-19$ & 10.5 \\
21 & 83 & $6-50$ & 11.5 \\
23 & 9 & $5-40$ & 9 \\
25 & 11 & $5-12$ & 8 \\
\hline
\end{tabular}

safe even at withdrawal of anticoagulation or antiplatelet treatment in $92 \%$ and $80 \%$ of the patients, respectively. The risk of late TE complications impact with an incidence of 3.8\% and a linearized rate of $0.79 \% / p t-y$ (CI, 0.60-1.01).

The major indication for long-term anticoagulation was atrial fibrillation. Valve thrombosis and lethal TE were encountered in $1(0.02 \% / \mathrm{pt}-\mathrm{y})$ and another $9(0.7 \%$ pt-y) patients in this series, respectively, and the potential hazard of anticoagulant-induced hemorrhage was significantly low $(\mathrm{n}=4$, $0.3 \%$ ) with a linearized rate of $0.06 \% / \mathrm{pt}-\mathrm{y}$ (CI, $0.02-0.15$ ).

The incidence of $3.4 \%$ TE complications in patients older than 65 years of age could be explained by the fact that the average patient age in the series was over 73 years and the risk of cerebral accidents developing from unrecognized cerebrovascular lesions without cardiac surgery was already high. ${ }^{26}$ The disparity in TE rates between our series and recently published data with porcine valves is evident. ${ }^{5,18,21-23,25}$ The lower propensity for TE in our cohort with the Mitroflow pericardial valve relates to the quality of the tissue and the design of the prosthesis. Although the exact etiology of early TE is not widely established, our experience has indicated that many patients could benefit from anticoagulant treatment for the initial 6 weeks after bioprosthetic aortic valve replacement. In the presence of one or more factors associated with an increased risk of TE (atrial fibrillation, enlarged left atrium with or without thrombus, recurrent atrial fibrillation after ablation), such patients with tissue valves should receive lifelong anticoagulant therapy.

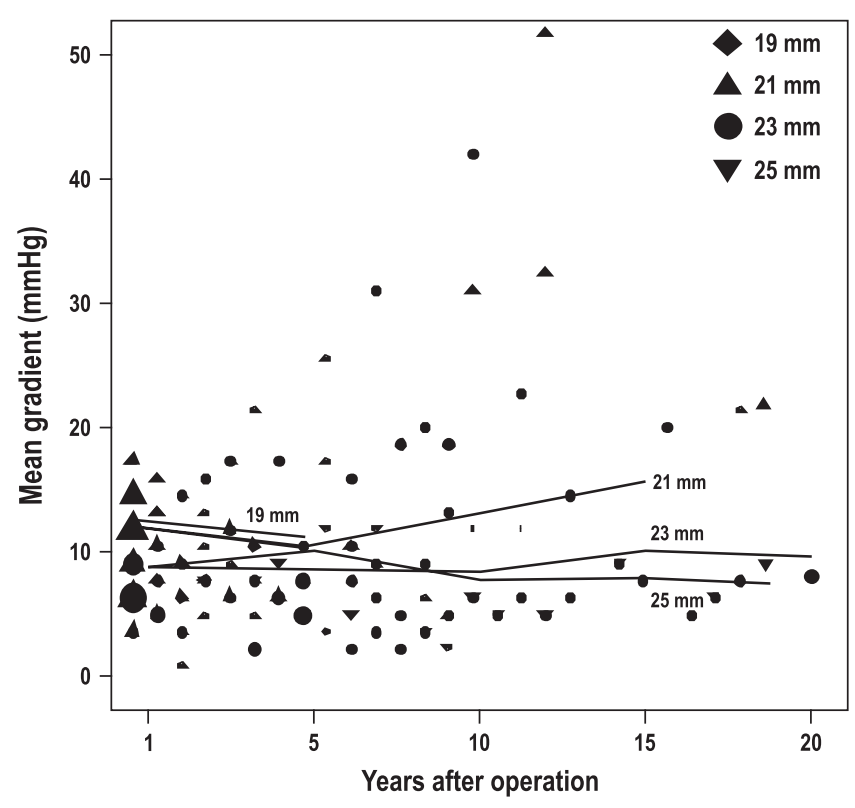

Figure 5. Time-related transvalvular mean gradients in relation to labeled valve sizes. Each symbol represents a labeled valve size. Solid lines represent time-related estimates of median values for each prosthesis. 


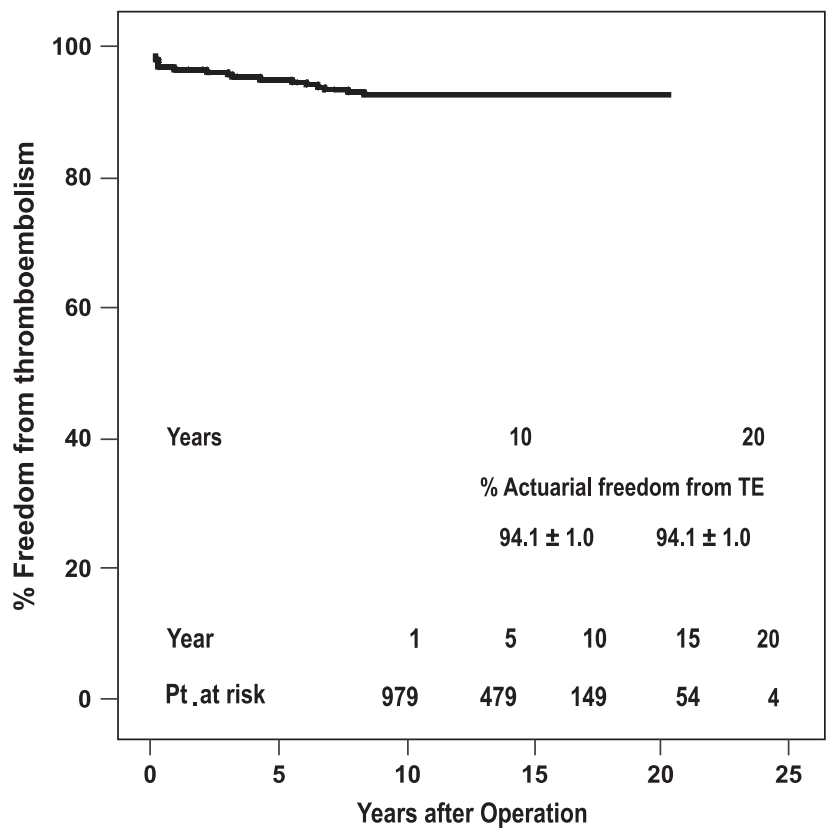

Figure 6. Actuarial freedom from thromboembolism (TE) after pericardial aortic valve replacement.

Concomitant coronary artery bypass graft operation was not found to be a risk factor for operative death. The low patient survival of $6 \%$ at 21 years with a median probability of survival time of 6.8 years is attributed to the average patient age of 73 years at implantation in our series, and it is in line with the results obtained from meta-analysis of life expectancy, which was 10.7 years for a 65 -year-old patient after aortic valve replacement. ${ }^{29}$

Furthermore, after 15 years the Kaplan-Meier estimates for patient survival are not as reliable as the initial estimates because of the limited number of patients at risk beyond 15 years. This translates in the mean follow-up per patient, which is 4.07 years per patient in the present study and 4.85 years per patient in the 2003 study. ${ }^{8}$

Actuarial freedom from valve-related death in our series was $94 \%$ at 10 years and $83 \%$ at 20 years. The result is in line with data published by others. ${ }^{4,17,19}$ Although autopsies were not performed in some patients who died with known causes, they were performed in cases of unexplained or sudden death with some exceptions (religious or cultural). Figures on SVD were obtained at reoperation or autopsy. ${ }^{27}$ The available autopsy results did not show any acute SVD or leaflet rupture as a cause of death. The long-term patient mortality was caused much more commonly by patient-related factors than by the presence of the Mitroflow pericardial valve prosthesis, as described in the paragraph on long-term survival of this article. Valve-related death of $4.1 \%(25 / 615)$ was therefore low in our series and was overestimated as sud-

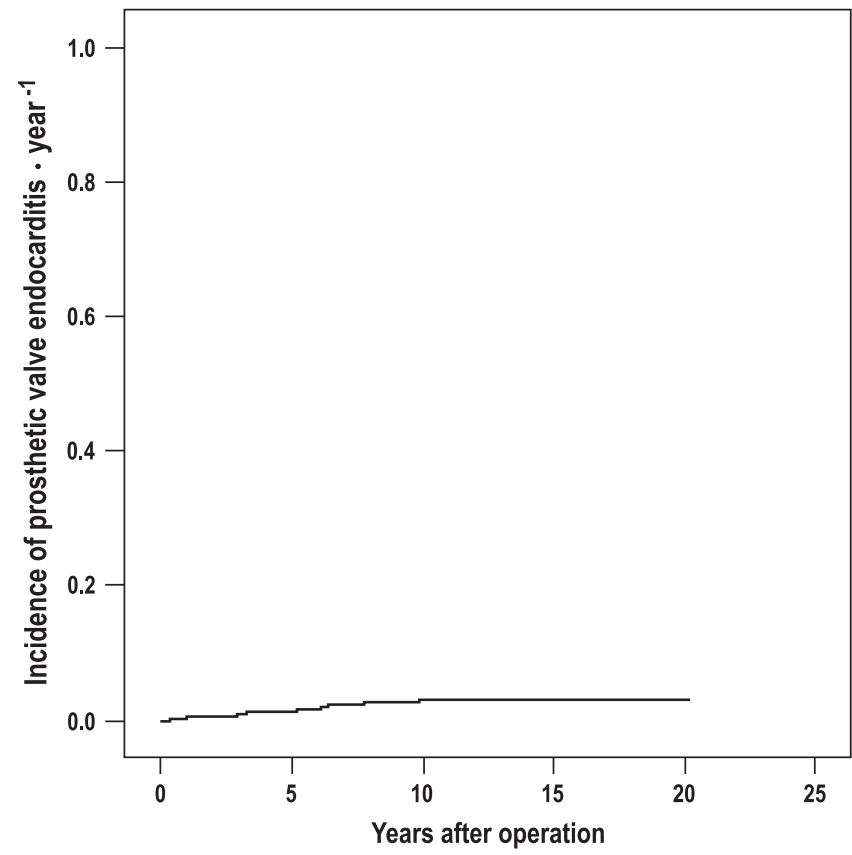

Figure 7. Hazard function of prosthetic valve endocarditis after pericardial aortic valve replacement. Constant hazard rate of events.

den or unexplained patient death and was the most common cause of valve-related death. There was no direct correlation between valve size and early or late death in patients with 19- to 21-mm and 23- to 25-mm Mitroflow bioprostheses $(P=.458$ and $P=.286)$. Further analysis to correlate with NYHA functional class revealed even better results for smaller valve sizes 19 to $21 \mathrm{~mm}(P=.003, P=.034)$.

Inasmuch as the physical capacity of elderly patients may diminish over time, we did not use change in NYHA class as a function for SVD or patient-prosthesis mismatch in these patients without echocardiographic evidence. The analysis has ruled out hemodynamically relevant patient-prosthesis mismatch and testifies to the excellent hemodynamic performance of small sizes of Mitroflow bioprostheses (mean transvalvular gradient $[\mathrm{mm} \mathrm{Hg}] /$ effective orifice area $\left[\mathrm{cm}^{2}\right]$ of 9.4 $\mathrm{mm} \mathrm{Hg} / 1.4 \mathrm{~cm}^{2}, 7.1 \mathrm{~mm} \mathrm{Hg} / 1.6 \mathrm{~cm}^{2}$, and $4.7 \mathrm{~mm} \mathrm{Hg} / 1.85$ $\mathrm{cm}^{2}$ for valve sizes $19 \mathrm{~mm}, 21 \mathrm{~mm}$, and $23 \mathrm{~mm}$, respectively) as compared with other bioprostheses. ${ }^{4,8,12-20}$

Repeated measurements of transvalvular mean gradients in relation to Mitroflow pericardial valve size across time in patients aged 65 years or older showed that mean transvalvular gradient at 5 years for valve sizes 19 to $23 \mathrm{~mm}$ was 12 to $5 \mathrm{~mm} \mathrm{Hg}$. This increased to 18 to $8 \mathrm{~mm} \mathrm{Hg}$ after 10 years and then remained stable at 15 and 20 years for valve sizes 21 and $23 \mathrm{~mm}$, respectively.

In contrast, patients younger than 65 years showed an increase in transvalvular mean gradient to 40 to $19 \mathrm{~mm} \mathrm{Hg}$ after 
10 years for valve sizes 21 and $23 \mathrm{~mm}$, which led to reoperation.

Patient-prosthesis mismatch was rare in our series, however, 2 patients with $19-\mathrm{mm}$ and $21-\mathrm{mm}$ valves in the supra-annular position were identified with a classic prosthesis-patient mismatch (effective orifice area, $0.8 \mathrm{~cm}^{2} /$ $\mathrm{m}^{2}$ ), which could have been avoided by myectomy and the Nicks procedure for enlargement of the noncoronary sinus, respectively.

Frater, ${ }^{17}$ Banbury, ${ }^{4}$ and their associates reported mean gradients of 22 to $15 \mathrm{~mm} \mathrm{Hg}$ and 22 to $12 \mathrm{~mm} \mathrm{Hg}$ for Carpentier-Edwards Perimount pericardial valve (Edwards Lifesciences, Irvine, Calif) sizes 19 to $25 \mathrm{~mm}$ at 12 and 17 years in patients at a mean age of 65 years, respectively. The gradients reported were somewhat greater than those we found in our cohort at 15 and 20 years. SVD observed in the first 5 years $(n=7$; linearized rate, $0.4 \% / p t-y$; CI, $0.18-0.87)$ in our cohort was confounded by sequelae of radiotherapy for cancer, implantation technical reasons including a rare patient-prosthesis mismatch, and subclinical endocarditis, whereas SVD beyond the 5-year period in the first decade was associated with age below 65 years. ${ }^{1,5,7,20,21}$

PVE was a rare event that occurred in $17(1.1 \%)$ patients, and the rate of recurrent infection was $0.8 \%(n=2)$. The actuarial freedom from PVE was $96.8 \% \pm 0.0 .9 \%$ and the linearized rate was $0.28 \% / \mathrm{pt}-\mathrm{y}(\mathrm{CI}, 0.14-0.44)$. The hazard rate for PVE was constantly very low. ${ }^{20}$

Our results suggest that the freedom from valve-related SVD, as well as the freedom from reoperation, and the TE rate are all very competitive with results published for other bioprostheses. ${ }^{17,18,21-25}$ The freedom from SVD and reoperation are age related, as is the case in other reports of series with bioprostheses. ${ }^{17,18,21,24}$ These data support our proposals that the Mitroflow prosthesis is the valve of choice in patients over the age of 65 to 70 years and a logical and safe choice for patients younger than 65 years of age with comorbidities.

\section{Conclusions}

The Mitroflow pericardial bioprosthesis exhibits very low pressure gradients combined with easy implantability. After 2 decades of follow-up, the Mitroflow pericardial aortic valve continues to be a valve of choice with a predictable low rate of valve-related events, particularly for patients over the age of 65 to 70 years and others with comorbidities.

We are grateful to Anne M. Gale, ELS, for editorial assistance, Astrid Benhennour for bibliographic support, and Carla Weber for providing the graphics.

\section{References}

1. Roselli EE, Smedira NG, Blackstone EH. Failure modes of the Carpentier-Edwards pericardial bioprosthesis in the aortic position. J Heart Valve Dis. 2006;15:421-8.
2. Scully H, Goldman B, Fulop J, Butany J, Tong C, Azuma J, et al. Fiveyear follow-up of Hancock pericardial valves: management of premature failure. J Card Surg. 1988;3(3 Suppl):397-403.

3. Leandri J, Bertrand P, Mazzucotelli JP, Loisance D. Mode of failure of the Mitroflow pericardial valve. J Heart Valve Dis. 1992;1:225-31.

4. Banbury MK, Cosgrove DM 3rd, Thomas JD, Blackstone EH, Rajeswaran J, Okies JE, et al. Hemodynamic stability during 17 years of the Carpentier-Edwards aortic pericardial bioprosthesis. Ann Thorac Surg. 2002;73:1460-5.

5. Minami K, Zittermann A, Schulte-Eistrup S, Koertke H, Körfer R. Mitroflow synergy prostheses for aortic valve replacement: 19 years experience with 1,516 patients. Ann Thorac Surg. 2005;80:1699-705.

6. Pomar JL, Jamieson WR, Pelletier LC, Gerein AN, Castella M, Brownlee RT. Mitroflow pericardial bioprosthesis: clinical performance to ten years. Ann Thorac Surg. 1995;60(2 Suppl):S305-10.

7. Yankah CA, Weng Y, Meyer R, Siniawski H, Hetzer R. Twenty-twoyear durability of Ionescu-Shiley pericardial aortic bioprosthesis implanted in a 49-year-old woman: a valuable insight into the performance of current pericardial bioprostheses. J Thorac Cardiovasc Surg. 2006; 132:427-8.

8. Yankah CA, Schubel J, Buz S, Siniawski H, Hetzer R. Seventeen-year clinical results of 1,037 Mitroflow pericardial heart valve prostheses in the aortic position. $J$ Heart Valve Dis. 2005; 14:172-80.

9. Moggio RA, Pooley RW, Sarabu MR, Christiana J, Ho AW, Reed GE. Experience with the Mitroflow aortic bioprosthesis. J Thorac Cardiovasc Surg. 1994;108:215-20.

10. Sjögren J, Gudbjartsson T, Thulin LI. Long-term outcome of the MitroFlow pericardial bioprosthesis in the elderly after aortic valve replacement. J Heart Valve Dis. 2006;15:197-202.

11. Thulin LI, Thilen UJ, Kymle KA. Mitroflow pericardial bioprosthesis in the aortic position. Low incidence of structural valve deterioration in elderly patients during an 11-year follow-up. Scand Cardiovasc J. 2000; 34:192-6.

12. Cosgrove DM, Lytle BW, Williams GW. Hemodynamic performance of the Carpentier-Edwards pericardial valve in the aortic position in vivo. Circulation. 1985;72(3 Pt 2):II146-52.

13. Garcia-Bengochea J, Sierra J, Gonzalez-Juanatey JR, Rubio J, Vega M, Fernandez AL, et al. Left ventricular mass regression after aortic valve replacement with the new Mitroflow 12A pericardial bioprosthesis. $J$ Heart Valve Dis. 2006;15(3):446-52.

14. David TE, Puschmann R, Ivanov J, Bos J, Armstrong S, Feindel CM, et al. Aortic valve replacement with stentless and stented porcine valves: a case-match study. J Thorac Cardiovasc Surg. 1998;116:236-41.

15. Sintek CF, Fletcher AD, Khonsari S. Small aortic root in the elderly: use of stentless bioprosthesis. J Heart Valve Dis. 1996;5(Suppl 3):S308-13.

16. Westaby S, Jin XY, Katsumata T, Arifi A, Braidley P. Valve replacement with a stentless bioprosthesis: versatility of the porcine aortic root. J Thorac Cardiovasc Surg. 1998;116:477-84.

17. Frater RW, Furlong P, Cosgrove DM, Okies JE, Colburn LQ, Katz AS, et al. Long-term durability and patient functional status of the Carpentier-Edwards Perimount pericardial bioprosthesis in the aortic position. J Heart Valve Dis. 1998;7:48-53.

18. Jamieson WR, David TE, Feindel CM, Miyagishima RT, Germann E. Performance of the Carpentier-Edwards SAV and Hancock-II porcine bioprostheses in aortic valve replacement. J Heart Valve Dis. 2002;11: 424-30.

19. Minami K, Schereika S, Kortke H, Gleichmann U, Koerfer R. Long term follow-up of Mitroflow pericardial valve prostheses in the small aortic annulus. J Cardiovasc Surg (Torino). 1993;34:189-93.

20. Rao V, Jamieson WR, Ivanov J, Armstrong S, David TE. Prosthesis-patient mismatch affects survival after aortic valve replacement. Circulation. 2000;102(19 Suppl. 3):III5-9.

21. Borger MA, Ivanov J, Armstrong S, Christie-Hrybinsky D, Feindel CM, David TE. Twenty-year results of the Hancock II bioprosthesis. J Heart Valve Dis. 2006;15:49-55; discussion 55-6.

22. Khan SS, Trento A, DeRobertis M, Kass RM, Sandhu M, Czer LS, et al. Twenty-year comparison of tissue and mechanical valve replacement. J Thorac Cardiovasc Surg. 2001;122:257-69.

23. Legarra JJ, Llorens R, Catalan M, Segura I, Trenor AM, de Buruaga JS, et al. Eighteen-year follow up after Hancock II bioprosthesis insertion. J Heart Valve Dis. 1999;8:16-24. 
24. Smedira NG, Blackstone EH, Roselli EE, Laffey CC, Cosgrove DM. Are allografts the biologic valve of choice for aortic valve replacement in nonelderly patients? Comparison of explantation for structural valve deterioration of allograft and pericardial prostheses. $J$ Thorac Cardiovasc Surg. 2006;131:558-64. e4.

25. Hammermeister K, Sethi GK, Henderson WG, Grover FL, Oprian C, Rahimtoola SH. Outcomes 15 years after valve replacement with a mechanical versus a bioprosthetic valve: final report of the Veterans Affairs randomized trial. J Am Coll Cardiol. 2000;36:1152-8.

26. Butchart EG, Moreno de la Santa P, Rooney SJ, Lewis PA. Arterial risk factors and ischemic cerebrovascular events after aortic valve replacement. J Heart Valve Dis. 1995;4:1-8.
27. Edmunds LH Jr, Clark RE, Cohn LH, Grunkemeier GL, Miller DC, Weisel RD. Guidelines for reporting morbidity and mortality after cardiac valvular operations. J Thorac Cardiovasc Surg. 1996;112:708-11.

28. Nollert G, Miksch J, Kreuzer E, Reichart B. Risk factors for atherosclerosis and the degeneration of pericardial valves after aortic valve replacement. J Thorac Cardiovasc Surg. 2003;126:965-8.

29. Puvimanasinghe JP, Takkenberg JJ, Edwards MB, Eijkemans MJ, Steyerberg EW, Van Herwerden LA, et al. Comparison of outcomes after aortic valve replacement with a mechanical valve or a bioprosthesis using microsimulation. Heart. 2004;90:1172-8.

30. Blackstone EH, Kirklin JW. Death and other time-related events after valve replacement. Circulation. 1985;72:753-67. 